\title{
The Effect of a Backpack Hip Strap on Energy Expenditure While Walking
}

Ryan S. Delgado, Jamie Pigman, William Sullivan, Steven Leigh, Peter A. Hosick. Montclair State University, Montclair, NJ, USA

Previous studies have demonstrated that energy cost increases as the weight of the load increases, but few investigations have been conducted that focus on backpack carriage specifically. PURPOSE: To examine the effect of backpack hip strap use on walking energy expenditure while carrying a loaded backpack. METHODS: A crossover design was used in which 15 young, healthy male subjects walked at a self-selected pace for two 10-minute loaded backpack trials either with a hip strap (strapped) or without a hip strap (non-strapped). Oxygen consumption $\left(\mathrm{VO}_{2}\right)$, rating of perceived exertion (RPE), respiratory exchange ratio (RER), and heart rate (HR) were monitored throughout each 10-minute trial. Change scores from the $4^{\text {th }}$ to $10^{\text {th }}$ minute were calculated for each variable. A t-test was used to evaluate the difference between trials for each variable. RESULTS: The change in $\mathrm{VO}_{2}(-0.62 \pm 0.40$ vs. $0.33 \pm 0.23$, $p=0.04)$ and RPE $(1 \pm 0.25$ vs. $2 \pm 0.21, p<0.01)$ from the $4^{\text {th }}$ to the $10^{\text {th }}$ minute were different for the strapped versus non-strapped condition, respectively. There was no difference in the change in RER ( $0.04 \pm 0.01$ vs. $0.03 \pm 0.01, \mathrm{p}>0.05)$ or HR (3.53 \pm 0.93 vs. $4.07 \pm 1.39, \mathrm{p}>0.05)$ for the strapped versus unstrapped condition, respectively. CONCLUSIONS: These results suggest wearing a hip strap reduces the energy expenditure and perceived exertion in as little as 10 minutes of walking. The reduced energy expenditure found with using a hip strap may have a significant impact on an individual's ability to hike or march for extended periods of time. 